\title{
Adverse drug reaction
}

\section{Omeprazole and excessive sweating, if unrecognised, may lead to unnecessary investigations}

\author{
M Mamun, S Caddick, M A Siddiqi
}

The common side-effects of omeprazole and other proton pump inhibitors (PPIs) are well known (ie, headache, nausea, diarrhoea, and skin rash), but there are others, which are uncommon and therefore less widely known and which may be specifically related to one member of the group. They may not be serious, but being very non-specific and relatively unknown, may tempt a clinician to look for a cause other than the prescribed drug. Omeprazole-induced hyperhydrosis is probably the most important example in this category. In general, PPIs are well tolerated, and treatment of patients with ZollingerEllison syndrome with omeprazole in doses of 60 to $360 \mathrm{mg}$ a day for up to 6 years has not caused any serious side-effects. ${ }^{12}$ However, there have been occasional reports of serious idiosyncratic adverse reactions including hepatitis and renal failure with omeprazole.

\section{Case report}

A 50-year-old man was referred by his general practitioner for further investigations and management of excessive sweating and intermittently raised blood pressure. The family doctor particularly wished the specialist to exclude phaeochromocytoma as a cause of his symptoms.

The patient was known to have endoscopically assessed non-ulcer dyspepsia, and had been on omeprazole, $20 \mathrm{mg}$ a day, for about 3 years. His blood pressure was at times high, at $170 / 110 \mathrm{mmHg}$, but on most occasions it was within the normal range at $130 / 80 \mathrm{mmHg}$. $\mathrm{He}$ was a non-smoker, drank about six pints of alcohol per week, and 8-10 cups of hot drinks (tea \& coffee) a day. He was not on any other medication.

The excessive sweating (hyperhydrosis) was intermittent, lasting for about 30 mins, and would drench his underclothes. It would occur at any hour twice or three times a month, and there were no precipitating factors he could recall. He first noticed this after he was changed from cimetidine to omeprazole in August 1995. There were no other associated symptoms such as flushing, palpitations, chest pain, dizziness or angor amini. His appetite was good, and his weight stable.

On examination, he was a middle-aged man weighing 15 stone, with a blood pressure of $130 / 70 \mathrm{mmHg}$. There was no tremor, facial erythema or heart murmur. His epigastrium was soft, and non-tender, and there were no other significant findings. Routine tests were ordered, and urinary catecholamines and 5-hydroxyindole acetic acid (5-HIAA) were also checked. He was asked to stop omeprazole and take an antacid preparation for 6 weeks, when he was asked to return for further tests (eg, gut hormones level). By the next visit, his symptoms had disappeared, and all the routine tests, including urinary catecholamines and 5-HIAA were within normal limits. He was seen by a more experienced doctor this time who thought his symptoms were most likely to be omeprazole induced, and cancelled all further investigations. However, his dyspepsia got worse, and he was put back on omeprazole at his request at the next clinic with the return of hyperhydrosis. In the past, he had received other PPIs (lansoprazole) and $\mathrm{H}_{2}$-antagonists (ranitidine), but omeprazole relieved his symptoms the best, and he decided to continue on this despite the side-effect.

\section{Discussion}

Excessive sweating seems to be an occasional problem with omeprazole, but not with other PPIs. In the international data sheet of the product it has been described as an adverse event occurring in isolated cases with an estimated incidence of $<1 \%$ (personal communication, Astra Pharmaceuticals Ltd, Home Park, Herts WD4 8DH, UK). In an analysis of adverse reactions to omeprazole therapy in short and long term studies in over 2500 subjects, only one case of sweating attacks was mentioned. ${ }^{3}$ By June 1998, the UK Committee on Safety of Medicines (CSM) had received 53 reports of sweating suspected to be due to omeprazole, which represented $0.9 \%$ of 6149 reactions reported for this drug occurring in 3784 patients (personal communication, CSM Mersey, 70 Pembroke Place, Liverpool L69 $3 \mathrm{GF}, \mathrm{UK})$. It is important to realise that reporting does not necessarily mean a causal relationship, and may not always reflect the extent of the problem. However, in our case, the symptoms reappeared after re-introduction of the drug, which strengthens the causal association.

The precise mechanism for hyperhydrosis is not known, and literature is sparse in this connection. The drugs that are known to cause excessive sweating, such as cholinergic drugs (eg, pilocarpine), anticholinesterase agents (eg, eserine), or sympathomimetic drugs (eg, phenylephrine), do so by affecting the autonomic nervous system. With the former two there may be other symptoms of parasympa- 
thetic overactivity, for example, nausea, excessive salivation, abdominal cramps, diarrhoea, etc, while the latter, may be associated with palpitations, flushing, anxiety, etc. This man did not have any of these symptoms, and it is unlikely that excessive sweating in the case of omeprazole is directly related to autonomic involvement. Previously, there have been reports of endocrine adverse effects (15 cases of gynaecomastia, and 15 cases of erectile dysfunction world-wide till December 1991) associated with omeprazole, but again there has been no adequate pharmacological explanation for these. ${ }^{4}$

As omeprazole-associated hyperhydrosis may cause alarm, and lead to unnecessary and unpleasant investigations, it is important to emphasise this to all medical practitioners.

1 Lloyd-Davies KA, Rutgersson K, Solvell L. Omeprazole in the treatment of Zollinger-Ellison syndrome: a 4-year international study. Aliment Pharmacol Ther 1988;2:13-22.

2 Hardman JG, Gilman AG, Limbird LE. In: Goodman $\varepsilon$ Gilman's The pharmacological basis of therapeutics, 9th edn. New York: McGraw-Hill, 1996; pp 908.

\section{Learning points}

- omeprazole-associated excessive sweating is uncommon, but as omeprazole is one of the most widely prescribed drugs, it is important to bear in mind

- recognising this would help to prevent unnecessary alarm, unpleasant investigations and, at times, inappropriate specialist referral

Keywords: omeprazole; proton pump inhibitors; hyperhydrosis; adverse drug reaction

\footnotetext{
3 Solvell L. Safety aspects of omeprazole. Scand $\mathcal{F}$ Gastroenterol 1986;21:S118,129-33.

4 Lindquist M, Edwards RI. Endocrine adverse effects of omeprazole. BMF 1992;305:451-2.
}

Charles Wilson (Lord Moran) (1882-1977) was born at Skipton-on-Craven, Yorkshire, son of a local doctor. He qualified at St Mary's Hospital, Paddington (1908) where he was a contemporary of Alexander Fleming. He became physician (1919) and dean (1920) at St Mary's, personal physician to Sir Winston Churchill and PRCP (1941-1950). He helped to found the National Health Service with Aneurin Bevan (1948). He was created a peer in 1943 and died on 12 April 1977. - DG Fames 